\title{
Exploratory/Developmental Grants Phase II
}

National Cancer Institute

\section{Source}

National Cancer Institute. Exploratory/Developmental Grants Phase II. NCI Thesaurus. Code C20013.

The R33 award is to provide a second phase for the support for innovative exploratory and development research activities initiated under the R21 mechanism. 